\title{
Análise de fatores de resistência a Tospovirus em acessos de Solanum (secção Lycopersicon) ${ }^{1}$
}

\author{
Renata Maria de Oliveira ${ }^{2}$, Marcos Gomes da Cunha ${ }^{2}$, \\ Maria Esther Noronha Fonseca ${ }^{3}$, Leonardo Silva Boiteux ${ }^{3}$, Érico de Campos Dianese ${ }^{2}$
}

\begin{abstract}
Analysis of Tospovirus resistance factors

in Solanum (section Lycopersicon) accessions

The intensive and uninterrupted tomato cultivation has favored the establishment of several diseases that affect fruit yield and quality. Genetic resistance is the best method to control the disease called 'vira-cabeça' (caused by distinct species of the genus Tospovirus), being $S w-5$ the first resistance gene effectively identified to control it in tomato plants. This study aimed at identifying new potential sources of tospovirus resistance in wild Solanum (Lycopersicon) species, as well as performing phylogenetic analysis related to the evolutionary characteristics of the $S w-5 b$ gene, in accessions of wild tomato species. These analyses showed that the different tomato species belong to distinct evolutionary groups. Most of the accessions with wide-spectrum resistance to Tospovirus species correspond to allelic variants closely related to the original $S w-5$ b gene copy. However, resistant accessions of $S$. chilense and $S$. habrochaites are located in distinct phylogenetic groups, meaning that they may represent promising sources of new genes/alleles, providing wide resistance to tospovirus.
\end{abstract}

KEY-WORDS: Solanum lycopersicum L.; Sw-5; resistance genes.

\section{INTRODUÇÃO}

O cultivo ininterrupto e intensivo do tomateiro (Solanum lycopersicum L.) tem favorecido o estabelecimento de diversas doenças que afetam a produção e a qualidade dos frutos. Essas doenças são causadas por diversos fitopatógenos, sendo as de origem viral as que proporcionam maiores dificuldades de controle.

Entre os fitopatógenos virais que acometem o tomateiro se destacam diversas espécies pertencentes ao gênero Tospovirus (família Bunyaviridae). Responsáveis pela doença conhecida como "vira-cabeça-

\section{RESUMO}

O cultivo ininterrupto e intensivo de tomateiro tem favorecido o estabelecimento de diversas doenças que afetam a produção e a qualidade dos frutos. A resistência genética é o melhor método para o controle da doença chamada 'viracabeça' (causada por distintas espécies do gênero Tospovirus), sendo o $S w-5$ o primeiro gene de resistência efetivamente identificado para o seu controle no tomateiro. Objetivou-se avaliar novas potenciais fontes de resistência às tospoviroses, em germoplasma de espécies selvagens de Solanum (Lycopersicon), bem como conduzir análises filogenéticas relacionadas à característica evolutiva do gene $S w-5 b$, em acessos de espécies selvagens de tomateiro. Essas análises evidenciaram que as diferentes espécies de tomateiros pertencem a distintos grupos evolutivos. A maioria dos acessos com resistência ampla contra espécies de Tospovirus correspondem a variantes alélicas muito próximas da cópia original do gene $S w-5 b$. No entanto, acessos resistentes de $S$. chilense e $S$. habrochaites localizamse em grupos filogeneticamente distintos, indicando que eles podem representar fontes promissoras de novos genes/alelos, condicionando resistência ampla aos tospovírus.

PALAVRAS-CHAVE: Solanum lycopersicum L.; $S w-5$; genes de resistência.

-do-tomateiro", os tospovírus causam elevadas perdas anuais de produção (King et al. 2012).

O gênero Tospovirus possui grande diversidade de espécies que infectam uma vasta gama de hospedeiros e são transmitidas de maneira circulativa/propagativa, por diferentes espécies de tripes (Pozzer et al. 1996). Entre as espécies que infectam o tomateiro e outras hortaliças estão: Tomato spotted wilt virus (TSWV); Tomato chlorotic spot virus (TCSV); Groundnut ringspot virus (GRSV), que é a espécie prevalente no Brasil (Lopes \& Ávila 2005); Chrysanthemum stem necrosis virus (CSNV); Iris yellow spot virus (IYSV); e Zucchini lethal chlorosis

1. Trabalho recebido em mai./2015 e aceito para publicação em set./2015 (http://dx.doi.org/10.1590/1983-40632015v4534417).

2. Universidade Federal de Goiás, Escola de Agronomia, Goiânia, GO, Brasil.E-mails: renata_oliveira89@hotmail.com, mgcagro@gmail.com, edianese@ufg.br.

3. Empresa Brasileira de Pesquisa Agropecuária (Embrapa Hortaliças), Brasília, DF, Brasil. E-mails: maria.boiteux@embrapa.br, leonardo.boiteux@embrapa.br. 
virus (ZLCV), responsáveis por grandes danos econômicos à cultura (Pozzer et al. 1996, Bezerra et al. 1999).

Devido às dificuldades encontradas no controle do inseto vetor, o desenvolvimento de cultivares de tomate com resistência às tospoviroses é o melhor método de controle.

O primeiro gene identificado com amplo espectro de resistência aos tospovírus foi denominado $S w-5$ e descrito originalmente em Solanum peruvianum, espécie de tomate que não reage com infecção sistêmica, quando inoculada com isolados do "vira-cabeça" (Stevens et al. 1992). Porém, fontes de resistência alternativas também já foram identificadas em acessos de $S$. chilense, $S$. corneliomuelleri e S. lycopersicum (Stevens et al. 1992, Dianese et al. 2011). Diante desse fato, a seleção desses materiais permite o aumento gradual de variedades resistentes aos tospovírus. Mais recentemente, Scott et al. (2005) obtiveram acessos derivados de $S$. chilense com resistência a um isolado havaiano de TSWV capaz de quebrar a resistência conferida pelo gene $S w-5$.

Os genes de resistência se distribuem em populações de uma determinada espécie hospedeira e sua variabilidade está relacionada com as características intrínsecas de cada indivíduo. Essa variação ocorre, principalmente, devido a diferentes tipos de mutações, incluindo deleções, inserções e substituições de nucleotídeos, bem como por eventos de recombinação que podem levar à inativação ou ativação de um determinado gene, ou alteração nos níveis de expressão da resistência (Suzuki et al. 1992).

Objetivou-se, no presente estudo, avaliar novas fontes potenciais de resistência às tospoviroses, em germoplasma de Solanum (Lycopersicon), bem como conduzir análises filogenéticas relacionadas à característica evolutiva do gene $S w-5$ b, em acessos de diferentes espécies selvagens de tomateiro. Para tanto, utilizou-se de um marcador gene-específico para gerar informações sobre a variabilidade alélica deste fator de resistência.

\section{MATERIAL E MÉTODOS}

Avaliou-se a presença do fator de resistência $S w-5$ b, por análise molecular, em 62 linhagens e variedades comerciais de tomateiro. Os genótipos foram provenientes do programa de melhoramento do grupo CVR Plant Breeding, localizado na cidade de Rio Verde (GO), e não foram testados quanto à resistência/suscetibilidade a Tospovirus. Dez materiais genéticos promissores para resistência a tospovírus, pertencentes ao Banco de Germoplasma da Embrapa Hortaliças (Brasília - DF), também foram avaliados. Essa coleção foi composta por acessos selvagens e três cultivares comerciais portadoras do gene de resistência $S w-5$ b. Todas as análises foram realizadas no Laboratório de Biologia Molecular da Escola de Agronomia da Universidade Federal de Goiás, em 2013.

As semeaduras foram efetuadas em bandejas compostas por 128 células de germinação, contendo substrato agrícola comercial (Plantmax ${ }^{\circledR}$ ). Quando as plântulas apresentavam pelo menos um par de folhas verdadeiras, procedeu-se ao transplante de três mudas para vasos de 3,0 L, contendo solo autoclavado. As plantas foram mantidas em casa-de-vegetação até apresentarem quantidade de folhas suficiente para a realização das análises moleculares.

Os acessos foram analisados para confirmação da presença do gene de resistência $S w$ - 5 b e posterior análise evolutiva desta região genômica do tomateiro. Para isso, o DNA de cada acesso foi purificado como descrito por Boiteux et al. (1999), utilizando-se o método CTAB 2X, modificado com passos extras de purificação com solventes orgânicos. Após a extração de DNA, foi realizada Polymerase Chain Reaction (PCR), para confirmar a presença da região promotora do gene de resistência $S w-5$ nos diferentes acessos de tomateiro. Para tanto, foi utilizado um marcador derivado do gene $S w-5$, denominado $S w-5-2$ (F = 5' AATTAGGTTCTTGAAGCCCATCT 3' $\mathrm{R}=5$ ' TTCCGCATCAGCCAATAGTGT 3'), descrito por Dianese et al. (2010).

O DNA foi amplificado utilizando-se $1 \mu \mathrm{g}$ de DNA total; $1 \mu \mathrm{L}$ de tampão para PCR 10X (Invitrogen); $0,3 \mu \mathrm{L}$ de $\mathrm{MgCl}_{2} 50 \mathrm{mM} ; 0,7 \mu \mathrm{L}$ de dNTP 2,5 mM; 100 ng de cada primer; 0,5 unidades de Taq DNA polimerase (Invitrogen); e água para volume final de $10 \mu \mathrm{L}$. As reações foram realizadas em termociclador Biocycler (Biosystems ${ }^{\circledR}$ ), de acordo com o seguinte programa: desnaturação a $94{ }^{\circ} \mathrm{C}$, por 2 minutos; 29 ciclos compostos por $94{ }^{\circ} \mathrm{C}$ por 30 segundos, $50{ }^{\circ} \mathrm{C}$ por 1 minuto e $72{ }^{\circ} \mathrm{C}$ por trinta segundos; e extensão final a $72{ }^{\circ} \mathrm{C}$ por 5 minutos. Todos os produtos de PCR foram visualizados em gel de agarose $1,5 \%$, em tampão TBE.

A partir da análise inicial obtida com o marcador $S w-5-2$ e da observação do padrão de bandas obtido no material selvagem de tomateiros, um primer 
"forward", que se alinha em uma região interna da cópia funcional do gene $S w-5(S w-5 b)$, denominado $S w$-5-B 1 (5'-ACCGGTGAAGTATTTCCCCAA-3'), foi utilizado em combinação com o primer $S w-5-2 \mathrm{~F}$. As bandas obtidas foram visualizadas em gel de agarose $1 \%$ e purificadas utilizando-se o Purelink Quick Gel Extraction Kit (Invitrogen ${ }^{\circledR}$ ) e, posteriormente, sequenciadas. A reação de sequenciamento foi realizada de acordo com o protocolo do kit BigDye ${ }^{\circledR}$, utilizando-se, para tanto, $2 \mu \mathrm{l}$ dos amplicons obtidos. $\mathrm{O}$ sequenciamento dos DNAs foi obtido por meio de um sequenciador automático ABI Prism 3100 (Applied Biosystems of Brazil, São Paulo, SP), pertencente ao Laboratório de Análise Genômica da Embrapa Hortaliças. A qualidade das sequências obtidas foi verificada utilizando-se o programa SeqMan (Allex 1999).

As sequências dos 13 acessos destinados à análise evolucionária do gene $S w-5$ b (dez acessos selvagens pertencentes ao BAG da Embrapa Hor- taliças, mais as cultivares 'Tospodoro', 'Viradoro' e 'Stevens') foram alinhadas com o programa CLC Main Workbench 6.9.2 (CLCBio, Aarhus, Denmark). Um dendrograma demonstrando a distância filogenética entre os genes/alelos foi gerado utilizando-se o método ClustalW do programa Mega 6.06 (Tamura et al. 2013).

\section{RESULTADOS E DISCUSSÃO}

A genotipagem do marcador $S w-5-2$ (Dianese et al. 2010), em todos os acessos (linhagens, variedades comerciais e híbridos) pertencentes ao banco da CVR Plant Breeding, indicaram três padrões de bandas de DNA (Figura 1). Somente o acesso do grupo CVR PI-1123023 (número 23, na Figura 1), variedade comercial, apresentou padrão de amplificação correspondente a plantas resistentes, com amplicon entre $550 \mathrm{pb}$ e $600 \mathrm{pb}$, assim como a variedade resistente 'Viradoro'. Cinquenta e sete

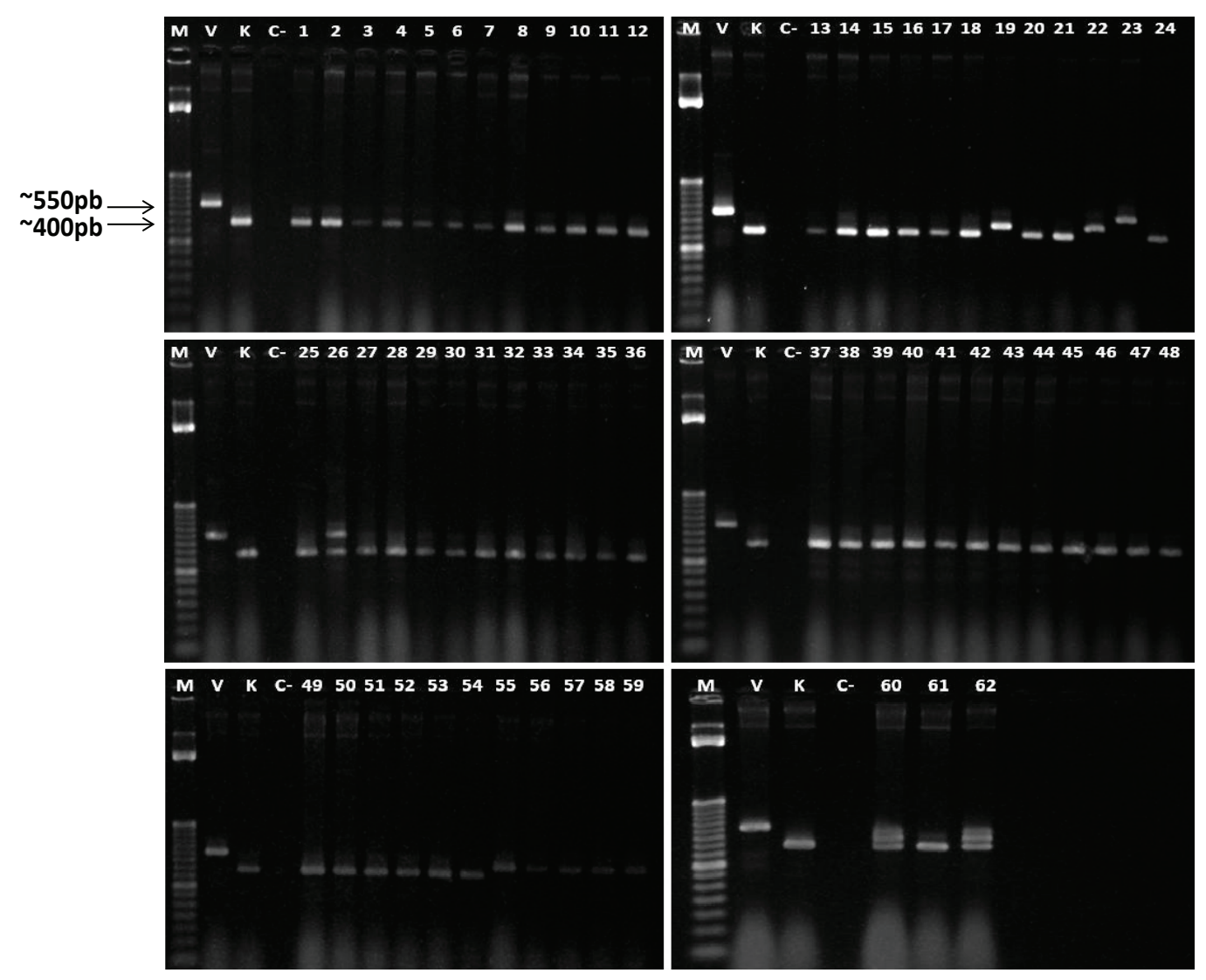

Figura 1. Perfil eletroforético de amplificação do DNA genômico dos acessos de tomateiro pertencentes ao grupo 'CVR Plant Breeding', utilizando-se o primer Sw-5-2 (Goiânia, GO, 2013). M - marcador 50 pb (Invitrogen); V - 'Viradoro' (controle resistente); K - 'Santa Cruz Kada' (controle suscetível); C - controle negativo com água; 1 a 28 - variedades CVR Plant Breeding; 29 a 62 - linhagens CVR Plant Breeding. 
acessos apresentaram amplicons de, aproximadamente, $400 \mathrm{pb}$, sendo considerados suscetíveis, por se alinharem com o padrão apresentado pelo controle suscetível da cultivar 'Santa Cruz KADA'.

Entre os 62 acessos genotipados com marcadores moleculares, quatro apresentaram padrão de bandas distinto. Os acessos 'PI-1123026', 'PI-1623027', 'PI-1623028' e 'CVR-2909' (canaletas 26, 60, 61 e 62 , respectivamente, na Figura 1) apresentaram duas bandas. A presença de duas bandas, provavelmente, ocorreu devido ao fato de a região amplificada estar em heterozigose e o marcador molecular empregado ser codominante (Dianese et al. 2010). Corrobora essa hipótese o fato de os acessos 'PI-1123026', 'PI-1623027' e 'PI-1623028' serem, muito provavelmente, heterozigotos. Para verificar se esses acessos de tomateiro se comportam como suscetíveis ou resistentes, é recomendável realizar inoculação mecânica, utilizando-se um isolado de tospovírus previamente identificado (Dianese et al. 2011).

A análise evolutiva do gene $S w-5$ foi conduzida com dez acessos selvagens previamente avaliados (Dianese et al. 2011) quanto à resistência a isolados de quatro espécies de tospovírus isoladas em tomateiros, no Brasil (Tabela 1). O DNA de cada acesso foi extraído e amplificado com o marcador ' $S w-5-2$ ' e, em seguida, amplificado novamente com a combinação dos primers 'Sw-5-2F' e 'Sw-5B 1', purificado e sequenciado.

Somente os acessos 'CNPH 457' (= 'Rey de los Tempranos') e o controle suscetível 'Santa Cruz Kada' (K) apresentaram amplicons correspondentes ao padrão de suscetibilidade (Figura 2). Os demais acessos mostraram padrão de amplicons similar ao de resistência, apresentando bandas com peso molecular entre $550 \mathrm{bp}$ e $600 \mathrm{bp}$.

Maluf et al. (1991) indicaram a cultivar 'Rey de los Tempranos' como o único acesso de S. lycopersicum com tolerância a isolados de TSWV. Durante o período de 1986 a 1989, a partir do cruzamento de 'Rey de los Tempranos' com outras espécies de tomate, obtiveram-se linhagens que, quando submetidas à alta e baixa pressão do isolado de TSWV, apresentavam respostas diferentes, indicando segregação para o gene de resistência. $\mathrm{Na}$ análise de resistência realizada por Dianese et al. (2010), em busca de fontes de resistência a tospovírus, o acesso 'Rey de los Tempranos' foi suscetível a isolados de GRSV. No entanto, em ensaios posteriores, esse acesso mostrou resistência específica contra isolados de TSWV.

Após a análise das sequências, utilizando-se a ferramenta BLAST (Altschul et al. 1990), foi constatado que os acessos 'CNPH 938', 'CNPH 939' e 'CNPH 1194' apresentam maior grau de identidade $(99 \%)$ com a sequência original do gene $S w-5 b$ caracterizado no tomateiro 'Stevens' - acesso AY007366.1 (Spassova et al. 2001). O acesso 'CNPH 457' apresentou o menor grau de similaridade $(81 \%)$. As cultivares comerciais 'Viradoro' e 'Tospodoro' apresentaram $98 \%$ de similaridade, quando comparadas com a sequência do acesso AY007366.1.

Tabela 1. Reação de acessos de Solanum (Lycopersicon) inoculados mecanicamente com isolados de tospovírus das espécies Groundnut ringspot virus (GRSV), Chrysanthemum stem necrosis virus (CSNV), Tomato spotted wilt virus (TSWV) e Tomato chlorotic spot virus (TCSV), analisados por meio de ELISAㄹ (Brasília, DF, 2009).

\begin{tabular}{|c|c|c|c|c|c|c|}
\hline \multirow{2}{*}{$\begin{array}{l}\text { Acesso } \\
\text { CNPH }\end{array}$} & \multirow{2}{*}{$\begin{array}{l}\text { Nome } \\
\text { comum }\end{array}$} & \multirow[t]{2}{*}{ Espécie } & \multicolumn{4}{|c|}{$\begin{array}{c}\text { Número de plantas positivas em ELISA/ } \\
\text { número de plantas avaliadas }\end{array}$} \\
\hline & & & GRSV & TSWV & TCSV & CSNV \\
\hline 101 & PI 306811-67-N-4 & S. peruvianum & $01 / 21$ & $00 / 21$ & $00 / 21$ & $00 / 15$ \\
\hline 410 & LA 1967 & S. chilense & $04 / 28$ & $03 / 22$ & $03 / 27$ & $04 / 10$ \\
\hline 421 & PI 127827 & S. habrochaites & $00 / 28$ & $06 / 27$ & $01 / 22$ & $00 / 11$ \\
\hline 457 & Rey de Los Tempranos & S. lycopersicum & $07 / 11$ & NA & NA & NA \\
\hline 786 & CGO 6713 & S. peruvianum & $00 / 28$ & $00 / 27$ & $01 / 27$ & $00 / 11$ \\
\hline 933 & LA 1677 & S. peruvianum & $03 / 28$ & $02 / 22$ & $01 / 22$ & $00 / 11$ \\
\hline 936 & LA 111 & S. peruvianum var. dentatum & $02 / 25$ & $00 / 24$ & $01 / 18$ & $00 / 08$ \\
\hline 938 & LA 1113-1 & S. corneliomuelleri & $00 / 20$ & $01 / 22$ & $01 / 22$ & $00 / 06$ \\
\hline 939 & LA $1113-2$ & S. corneliomuelleri & $01 / 21$ & $01 / 26$ & $02 / 26$ & $00 / 11$ \\
\hline 1194 & CGO 8200 & S. peruvianum & $00 / 28$ & $00 / 22$ & $00 / 22$ & $00 / 06$ \\
\hline- & Viradoro & S. lycopersicum & NA & NA & NA & NA \\
\hline- & Tospodoro & S. lycopersicum & NA & NA & NA & NA \\
\hline
\end{tabular}

${ }^{1}$ Informações adaptadas de Dianese et al. (2009); NA: não avaliado. 


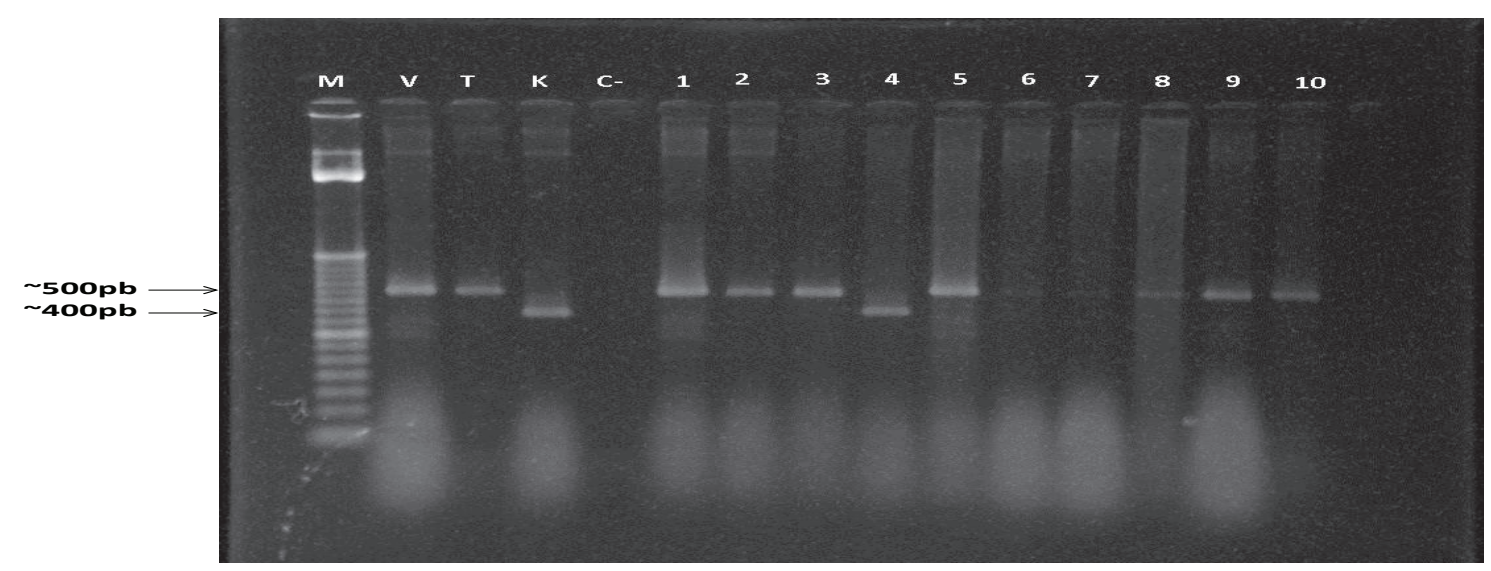

Figura 2. Perfil eletroforético referente à amplificação do DNA genômico dos acessos do Banco de Germoplasma da Embrapa Hortaliças (Goiânia, GO, 2013). M - marcador 50 pb (Invitrogen); V - 'Viradoro' (controle resistente); T - 'Tospodoro'; $\mathrm{K}$ - 'Santa Cruz Kada' (controle suscetível); 1 - 'CNPH 101'; 2 - 'CNPH 410'; 3 - 'CNPH 421'; 4 - 'CNPH 457'; 5 - 'CNPH 786'; 6 - 'CNPH 933’; 7 - 'CNPH 936’; 8 - 'CNPH 938'; 9 - 'CNPH 939'; 10 - 'CNPH 1194'.

O acesso 'CNPH 1194' pertence à espécie S. peruvianum, que foi a fonte inicial e mais importante de fatores de resistência a tospovírus, e que passou a ser introgredida em diferentes variedades comerciais de tomate (Stevens et al. 1992). Isso explica os maiores níveis de identidade observados entre acessos desta espécie e a fonte original do gene Sw-5b. Já 'CNPH 938' e 'CNPH 939' pertencem à espécie S. corneliomuelleri (Dianese et al. 2010). Estes dois acessos também foram resistentes à espécie de Potyvirus denominada Pepper yellow mosaic virus (PepYMV). Com isso, esses acessos possuem uma possível fonte alternativa de genes de resistência para programas de melhoramento que preconizam o controle desses vírus.

As sequências obtidas a partir dos acessos de Solanum (secção Lycopersicon) foram alinhadas e comparadas com a sequência do acesso original contendo o gene $S w-5$ b (AY007366.1), disponível no GenBank (Figura 3). O alinhamento permitiu inferir que o acesso 'CNPH 936', originário de S. peruvianum var. dentatum, possui uma inserção de 26 nucleotídeos a partir da posição 19, mutações pontuais do tipo transição e transversão e deleção em alguns pontos da sequência. Uma grande deleção da posição que vai de $70 \mathrm{pb}$ a $99 \mathrm{pb}$ e mutações de ponto foram observadas no acesso 'CNPH 457' (= 'Rey de los Tempranos') e, também, no acesso $S$. chilense 'CNPH 410', que apresentou $85 \%$ de identidade com a sequência original ('Stevens' - acesso AY007366.1).

Mutações pontuais também foram observadas nos acessos 'CNPH 101'e 'CNPH 786' (transversão e transição), inserção no 'CNPH 933', transição, transversão e deleção nos acessos 'CNPH 421' e 'CNPH 1194'. Nos acessos 'CNPH 938' e 'CNPH 939' ocorreu somente um ponto de transição, denotando o seu alto nível de identidade com a sequência original do gene $S w-5$ b descrita por Spassova et al. (2001).

Dessa forma, as mutações (deleção, inserção e mutações pontuais) são responsáveis pelos polimorfismos genéticos das vias de transdução de sinais, resultando em diferentes níveis de resistência. Esses resultados podem ser confirmados a partir da inoculação mecânica com isolados de tospovírus e pela diversidade fenotípica da expressão de sintomas ou reação de hipersensibilidade (Dianese et al. 2011).

A análise filogenética (Figura 4), obtida via método Neighboor-Joinning (Mega 6.06), agrupou, no mesmo ramo, os acessos 'CNPH 936', 'CNPH 939', 'CNPH 933', 'CNPH 101', 'CNPH 938' e 'CNPH 1194' com as cultivares 'Viradoro', 'Tospodoro' e 'Stevens', indicando que pertencem ao mesmo grupo evolutivo. Logo, é provável que as diferenças nas sequências desses acessos não sejam suficientes para tornar inativa a resistência observada nas variedades controle ('Viradoro', 'Tospodoro' e 'Stevens').

O acesso $S$. peruvianum 'CNPH 786' apresentou mutações de ponto; o acesso ' $\mathrm{CNPH} 410$ ' (S. chilense) apresentou, em sua sequência, eventos de deleção, inserção e mutações de ponto; e 'CNPH 421' (S. habrochaites) mostrou mutações de ponto e deleção, enquanto o acesso 'CNPH 457', 'Rey de los Tempranos' (S. lycopersicum), apresentou 
elevada incidência de deleção. Esses polimorfismos justificam o agrupamento desses acessos em ramos significativamente distintos, podendo-se relacioná-los com outros grupos evolutivos.

Pryor \& Ellis (1993) relataram que o estudo da diversidade e organização genômica de genes de resistência abre novas perspectivas para o entendimento da evolução desses genes, auxiliando
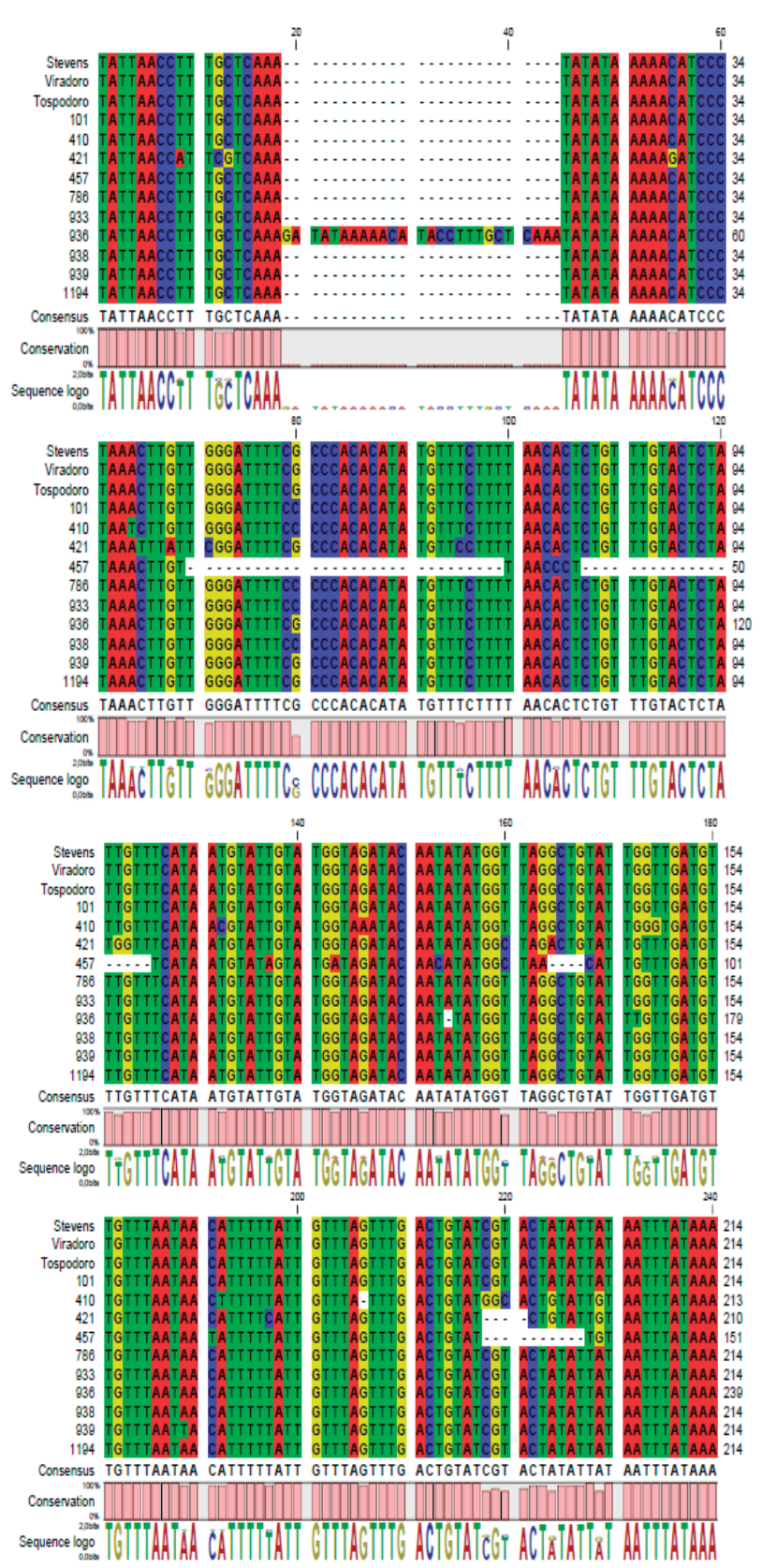
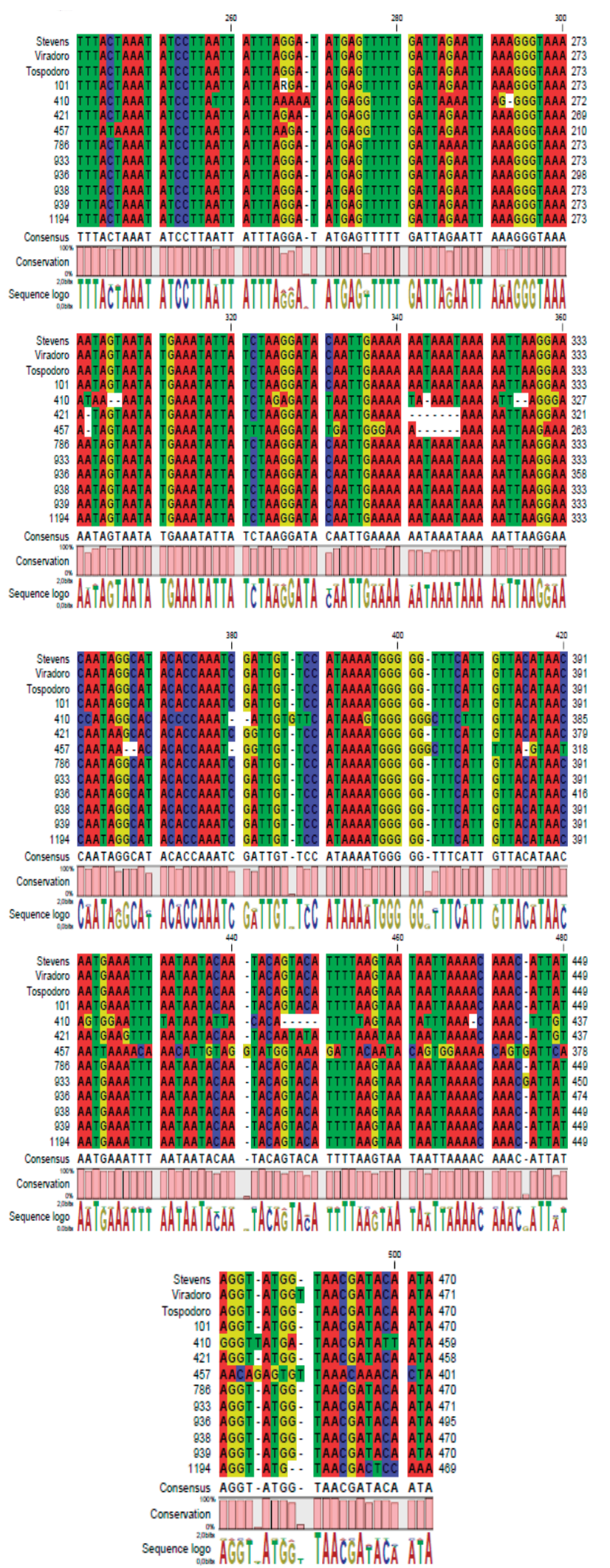

Figura 3. Alinhamento das sequências de nucleotídeos dos acessos CNPH, em relação à sequência base 'Stevens' (Goiânia, GO, 2013). 'Stevens': sequência do gene $S w$-5b código NCBI AY007366.1; 'Viradoro': acesso comercial resistente a tospovírus; 'Tospodoro': acesso comercial resistente a tospovírus; 101: 'CNPH 101'; 410: 'CNPH 410'; 421: 'CNPH 421'; 457: 'CNPH 457’; 786: ‘CNPH 786'; 933: ‘CNPH 933'; 936: 'CNPH 936'; 938: 'CNPH 938'; 939: 'CNPH 939'; 1194: 'CNPH 1194’. 


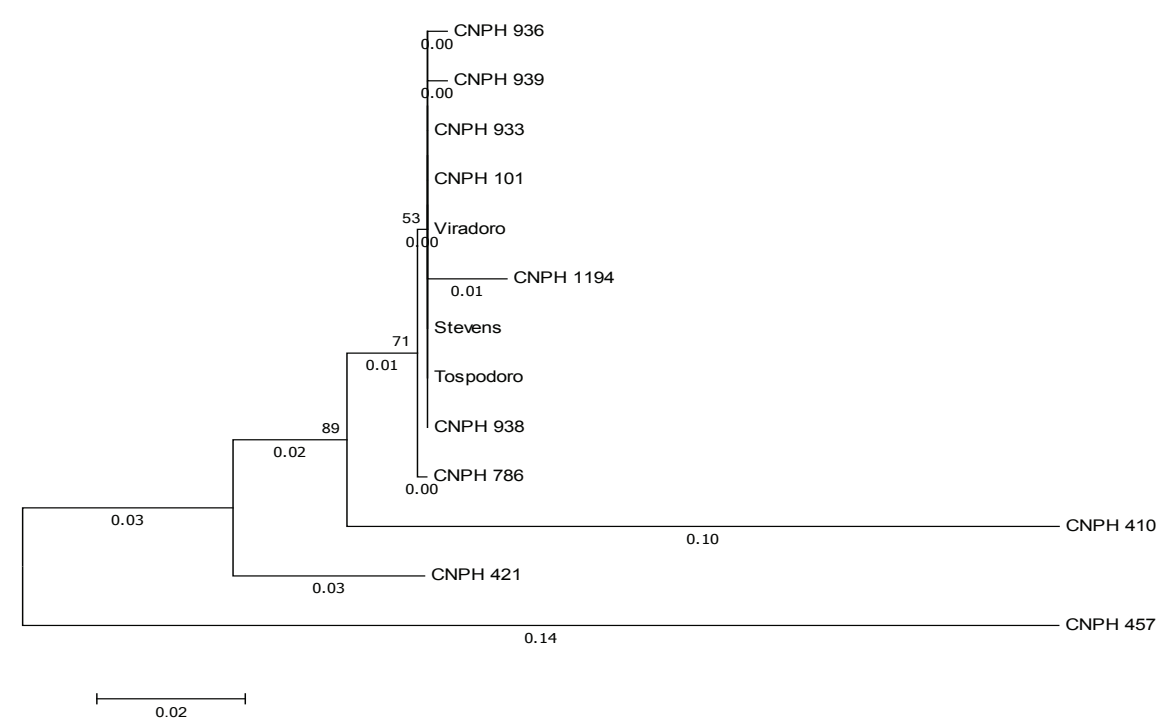

Figura 4. Análise filogenética obtida pelo alinhamento múltiplo, por meio de Neighbor-joining (Mega 6.06), para os acessos selvagens e cultivares de tomateiro do Banco de Germoplasma da Embrapa Hortaliças (Goiânia, GO, 2013).

no desenvolvimento de estratégias eficientes para incorporar fatores de resistência e para o controle das doenças. Nesse estudo, verifica-se que as plantas possuem muitos genes raça- ou espécie-específicos, os quais são mapeados em poucos loci. Tais regiões genômicas podem ser constituídas por genes isolados ou por grupos de genes ligados e organizados de forma sequencial e, também, por genes que contêm diferentes alelos. O número de genes de resistência, bem como o seu mapeamento, têm sido determinados para diversos patossistemas (Pryor \& Ellis 1993).

Segundo Burdon \& Silk (1997), as combinações de seleção, deriva genética, migração e mutação definem a estrutura genética e a diversidade das populações dos fitopatógenos. O papel de cada um desses fatores pode variar intensamente de acordo com as interações planta/patógeno, entre os estádios do ciclo epidemiológico e associações de ecossistemas naturais ou agrícolas (Burdon \& Silk 1997).

Os genes de resistência e os fatores de virulência dos patógenos devem ser sempre estudados, visto que a evolução desses, a partir de eventos de recombinação e mutações, ocorre, frequentemente, como resposta adaptativa das espécies (Barbieri \& Carvalho 2001). Além da identificação de espécies que conferem resistência a determinados fitopatógenos e do estudo da evolução dos genes, faz-se necessário, também, realizar a análise de segregação dos genes de resistência dessas espécies, principalmente quando se trata de espécies selvagens, para se obter uma fonte confiável de resistência em programas de melhoramento.

\section{CONCLUSÕES}

1. Apenas acessos com variantes alélicas muito próximas do gene $S w$-5b apresentam a característica de resistência ampla a diferentes espécies de Tospovirus.

2. Os acessos selvagens das espécies $S$. chilense e $S$. habrochaites possuem padrão de bandas compatível com a resistência conferida aos tospovírus e podem fornecer alelos diferenciados aos obtidos a partir de $S$. peruvianum, já que se agrupam em ramos filogeneticamente distintos.

\section{REFERÊNCIAS}

ALLEX, C. F. Computational methods for fast and accurate DNA fragment assembly. 1999. $211 \mathrm{f}$. Tese (Doutorado em Ciências da Computação) - University of Wisconsin, Madison, 1999.

ALTSCHUL, S. F. et al. Basic local alignment search tool. Journal of Molecular Biology, London, v. 215, n. 1, p. 403-410, 1990.

BARBIERI, R.; CARVALHO, F. I. F. Coevolução de plantas e fungos fitopatogênicos. Revista Brasileira de Agrociência, Pelotas, v. 7, n. 2, p. 79-83, 2001. 
BEZERRA, I. C. et al. Increase of tospoviral diversity in Brazil with the identification of two new tospovirus species, one from Chrysanthemum and one from zucchini. Phytopathology, Saint Paul, v. 89, n. 11, p. 823-830, 1999.

BOITEUX, L. S. et al. Effects of plant tissue and DNA purification method on RAPD-based genetic fingerprinting analysis in carrot. Journal of the American Society of Horticultural Science, Alexandria, v. 124, n. 1, p. 32-38, 1999.

BURDON, J. J.; SILK, J. Sources and patterns of diversity in plant-pathogenic fungi. Phytopathology, Saint Paul, v. 87, n. 7, p. 664-669, 1997.

DIANESE, C. E. Estratégias para o desenvolvimento de resistência ampla e durável em Solanum (Secção Lycopersicon) a Potyvirus e Tospovirus. 2009. 156 f. Tese (Doutorado em Fitopatologia) - Universidade de Brasília, Brasília, DF, 2009.

DIANESE, E. C. et al. Development of a locus-specific, co-dominant SCAR marker for assisted-selection of the Sw-5 (Tospovirus resistance) gene cluster in a wide range of tomato accessions. Molecular Breeding, Dordrecht, v. 25, n. 1, p. $133-142,2010$.

DIANESE, E. C. et al. Search in Solanum (section Lycopersicon) germplasm for sources of broad-spectrum resistance to four Tospovirus species. Euphytica, Wageningen, v. 180, n. 3, p. 307-319, 2011.

KING, A. M. Q. et al. Classification and nomenclature of viruses: ninth report of the International Committee on Taxonomy of Viruses. San Diego: Elsevier, 2012.

LOPES, C. A.; ÁVILA, A. C. de. Doenças do tomateiro. Brasília, DF: Embrapa Hortaliças, 2005.
MALUF, W. R.; BRAGHINI, M. T.; CORTE, R. D. Progress in breeding tomatoes for resistance to tomato spotted wilt. Revista Brasileira de Genética, São Paulo, v. 14, n. 2, p. 509-525, 1991.

POZZER, L. et al. Tospovirus: uma visão atualizada. Revisão Anual de Patologia de Plantas, Passo Fundo, v. 4, n. 1, p. 95-148, 1996.

PRYOR, T.; ELLIS, J. The genetic complexity of fungal resistance genes in plants. Advances in Plant Pathology, London, v. 10, n. 1, p. 281-305, 1993.

SCOTT, J. W.; STEVENS, M. R.; OLSON, S. M. An alternative source of resistance to tomato spotted wilt virus. Tomato Genetics Cooperative Report, Gainesville, v. 55, n. 1, p. 40-41, 2005.

SPASSOVA, M. I. et al. The tomato gene $S W 5$ is a member of the coiled coil, nucleotide binding, leucine-rich repeat class of plant resistance genes and confers resistance to TSWV in tobacco. Molecular Breeding, Dordrecht, v. 7, n. 2, p. 151- 161, 2001.

STEVENS, M. R.; SCOTT, S. J.; GERGERICH, R. C. Inheritance of a gene for resistance to tomato spotted virus (TSWV) from Lycopersicon peruvianum Mill. Euphytica, Wageningen, v. 59, n. 1, p. 9-17, 1992.

SUZUKI, D. T. et al. Introdução à genética. 4. ed. Rio de Janeiro: Guanabara Koogan, 1992.

TAMURA, K. et al. MEGA6: molecular evolutionary genetics analysis. Version 6.0. Molecular Biology Evolution, Chicago, v. 30, n. 12, p. 2725-2729, 2013. 